\title{
Cultural-Bound Meaning of Animal Names in Arabic
}

\author{
Juhaina Maen Al Issawi \\ Correspondence: Juhaina Maen Al Issawi, Jordan. \\ Received: February 21, 2021 \\ Accepted: March 24, 2021 \\ Online Published: March 27, 2021 \\ doi:10.5430/elr.v10n1p42 \\ URL: https://doi.org/10.5430/elr.v10n1p42
}

\begin{abstract}
The current study investigates the cultural-bound meaning of animal names in Arabic. The study aims at finding out the different meanings of these words fulfilled and how different cultures play a crucial role in altering these meanings. The study analyzed ten animal names qualitatively by providing the various meanings of Arabic literature: Quran, dictionaries, idioms, and proverbs. The study found out that these names have conveyed different meanings based on the culture and context by which they occur. It proves that each name has a denotative meaning that fixed and another connotative meaning that reflects the speakers' culture. The study also reveals that factors like appearances, behavior, intelligence, and characteristics usually trigger individuals to name humans after animal names. Moreover, the gender of the animal name is another factor that can alter the meaning completely.
\end{abstract}

Keywords: Animal names, Cultural- bound meaning, Denotation, Connotation.

\section{Introduction}

Similar to any other culture, animal names have cultural significance in Arab societies. Some of the Arab parents name their children after animals because the animal positive traits inspire them. That is to say, lots of Arab men and women are named after attractive and strong wild animals. Such a culture is deep-rooted in the ancient Arab history and cultures by which individuals are subjected and shaped by the surrounded nature and environment. It is worth mentioning that animals are respected in the middle eastern culture, where baiting animals is prohibited, especially for gambling or entertaining purposes. Accordingly, it is widespread to hear some expressions like "strong as an ox" or "cunning as a fox" that relates positive or negative human qualities to animals. The reference to animal names is rooted in the cultural folk stories (Nesi, 1995). Metaphorically speaking, the symbolic meaning of transfer animal names to human names is different from one culture to another. Ringmar (2016:113) stated that in Thailand, for example, it is widespread to complement a woman by saying that "she walks like an elephant." However, such an expression is considered very offensive and rude in the Jordanian culture because it implies that the woman has overweight, which is unacceptable socially.

However, describing the meaning of any word requires two main methods, namely: denotation and connotation. Whereas the former means the literal and precise meaning of the word as might be found in the dictionary, the latter refers to a wide range of positive and negative associative meanings, which most of the words inherently carry with them (Omar, 2012). The two levels of word meaning correlate together in the process of word definition. Although they are separate things; yet, the connotative meanings exist together with denotative meanings. Words can convey more than the literal and exact meanings of the words since they suggest or "connote" further values or meanings that are not conveyed in dictionaries. Therefore, Ahmad (2017:46), among others, insisted on the importance of the contextual factors in identifying the meaning of words. It depends mostly on the environmental factors that are surrounding the speakers. Accordingly, based on their background knowledge, the speakers started to make an association between the words and their correlation based on their perspectives. Semantically speaking, this can represent a new level of representation in the semantic representation.

The binary distinction between the denotative and connotative meaning of a given the word depends on the relationship between the word and its reference. In other words, the denotative meaning refers to the relationship between the linguistic sign and its referent or denotatum that existed in the real world. On the other hand, a word's connotative meaning composes different words' (lexemes) property such as literal, poetic, humorous, rhetorical, or legal properties. Despite the difference between the two levels of words, both denotative and connotative meanings contributed in determining a word's meaning in a given context. However, Scholars such as Berkeley and Hume perceived meaning as mental images. According to the mental image theory, the concept is perceived in the mind in the absence of the "immediate sensorial stimulus" (Pinker, 1988:17). 
In this discussion, one key concept is the "mental schema theory," based on which the brain constructs knowledge. Nishida (1999) contained that a schema is a unit of knowledge organized for a particular subject or unites based on a previous experience and is accessed to direct existing actions. One type of which is cultural schema based on which people understand individuals from other cultures. Garro (2000) argued that cultural schema is usually created from previous personal experiences through the interaction between members belonging to the same culture. From this point, the present study suggests the difference in meanings between animal names based on the speakers' cultural differences. Hence, even though animal names have fixed literal meanings in dictionaries, these names correlate with cultural-bound meanings. It will be dissuaded later on in this study.

\section{Literature Review}

Recent studies have been showing the surge of interest in examining the social significance of animal names. Previous research, therefore, tried to show the different connotative meanings of animal names and correlations between them and human traits. For instance, Nesi (1995) examined the figurative meanings related to various types' animal names. His study aims to show the correlation between the different animal types in different cultures. One crucial issue highlighted is that the difficulties that might face the learners in translating these words when used metaphorically. The study dealt explicitly with three animals, namely cat, cow, and mouse. The study found out that the participants think at the first time of the connotative meaning related to their culture when these animals are used figuratively.

Halupka-Resetar and Radic (2003) examined the metaphorical uses of animal names in addressing people in Serbian, whether abusively or affectionately. Their study tried to show how addressing people using animal names can express the attitudes of the speakers towards the addressee by examining 100 surveyed questionnaires. The study further analyzed the morphosyntactic structures and semantico-pragmatic by which animal names occur. The study's finding showed that animal names in Serbian are used more frequently abusively than as endearment. Animal characteristics such as size, eating habits, and intelligence are the main motivations of the metaphorical transfer of their names to humans.

Hsieh (2006) studied animal expressions from a semantic perspective. The study approaches the animal expressions through semantic molecules to explore semantic interaction. The study's main aim is to discover the cultural perspective towards animal names and how people view them differently. According to the study, these different views are due to the different mentalities of the people. The study found out that social attitudes are used to indicate distinct ideologies.

Al-makaui (2007) stated that the importance of names is existed because of their association with various factors. Among these are religious factors in the sense that names might derive its importance because it refers to a religious person or occasion. He proclaimed that since the creation of Adam, names reflect the people's knowledge and traditions. Arabs embraced their power and strength by calling themselves strong names because it was believed that the person has part of its name.

Sameer (2016) investigated the difference in the usage of animal names in Arabic and English proverbs. The researcher studied two animals in specific namely: dogs and horses. The analysis of the study was based on the framework of gathering Lakoff and Turner (1989) and Sperber and Wilson (1986) approach as well as Hsieh's (2006) approach of semantic molecules in an attempt to show whom different cultural backgrounds affect the usage and the perception of these proverbs. The study found out that cultural and cognitive values are transmitted from one generation to another.

Ahmmad (2017) maintained that the ideal speaker could generate infinite numbers of meanings from a single word. According to him, this can only be if speakers do not stick themselves to the literal meanings; instead, they also take the figurative meanings into account. He added that many factors play roles in interpreting words, such as grammar and sentential elements. In his study, he focused on the compound words and how they give a meaning that differs from the words they are formed of.

Shamsutdinova (2017) studied the proverbs related to animals in Arabic, English, and Tatar. The study attempted to find the different animals related proverbs. The sample proverbs were taken from the online press. The study focused on the number of animal proverbs in the three unrelated languages. The study concluded that proverbs, in general, are tools that are used to convey ones' point of view concerning one culture. Therefore, proverbs are affected by two factors: their tradition in ensuring the continuation of these proverbs and, on the other hand, their opportunity to adapt to new meanings. 
Animal names are one of the essential subjects that are drawn from cultural linguistics theories. For instance, Ben Salamh and Maalej (2018) examined the use of animal proverbs in two different dialects, namely, Saudi Arabic and Tunisian Arabic. The study examined several particular scenes in which animal names occur in proverbial discourse. The study found that proverbs related to animals have discourse-bound meaning that is dependent on the environment. Besides, it reveals some generic scenes when referring to the two sub-cultures when referring to animal names.

Other studies examined the cultural-bound meaning of one type of animal name. Al-Salem, Ali, and Alrashdan (2020) analyzed the use of bird names only in describing people in both Arabic and English. The study concerned more specifically with the extent to which the gender of the addresses affects the use of these names. The analysis of 24 native speakers of American and British English and 24 native speakers of Jordanian Arabic showed no significant differences regarding the frequencies of using bird names while describing people. On the other hand, the study revealed that Jordanians are more sensitive to gender when it comes to bird names.

Further cross-cultural studies revealed that animal names could be used metaphorically to refer to or address people. Al-Harahsheh and Al-Rousan (2020), for example, examined the pragmatic use of 44 animal names in Jordan. The study was conducted by distributing 100 surveys to native Arabic students at Yarmouk University to explore the animals' pragmatic meanings covered in the study. One primary pragmatic function of using animal names is to indicate the physical traits, intelligence, characteristics, and behavior of the addresses except for few cases where they were used to express negative traits such as ugliness, insult, and stupidity.

\subsection{The Aim of the Study}

This study aims at examining the different cultural meanings of words related to animal names. The study aims to find out the variation of the usage of animal terms based on different cultural perspectives and how these usages are modified through time. It also aims to show how each name has two layers of meanings: denotative and connotative. Furthermore, it attempts to show how the connotative meaning is cultural-bound and varies from one culture to another. To show such variations, the research provides different Arabic provers, idioms, and verses that are used on each animal name.

\subsection{Methodology}

In order to fulfill the purpose of the study, ten animal names are collected and analyzed. Although the words are collected randomly, the research intends to choose the most frequent animal names referred to in the daily speech. Then the words are analyzed qualitatively, not quantitatively, because the animal names are given a complete description of their meanings. Consequently, the words are first defined based on their denotative meanings taken from the dictionary. To be more specific, the dictionaries used the most in the identification of words in this research are Mojamh AL Maani and AL-Muajam AL-Wassit. In addition to Majma' al-amthal by Maydani (2013), most of the Arabic proverbs in this research are extracted. After giving the linguistic meanings of the animal names, the encyclopedic meanings are given by showing the words' different figurative and cultural meanings. Such analyses would not be done haphazardly; rather, it depends on the Arabic famous sayings and idioms in addition to their occurrences in poetry.

\section{Data Analyses}

This section is devoted to the analyses of the collected words. As mentioned earlier, the data is analyzed qualitatively, aiming to find an overall understanding of the research topic's characteristics and quality. Accordingly, each word is analyzed separately, providing the denotative meaning first as it is found in the Arabic dictionaries which fixed. The connotative meanings are then provided as they appear in Arabic proverbs, idioms, and poetic verses. The following are the subsections where each word is analyzed separately, starting with the dictionary meaning the encyclopedic meanings.

\subsection{Al Jamal (The Camel)}

In the ancient Arab world, camels are known for having great importance as primary nourishment and wealth sources. Mostly, the camel was the creature of burden used to transport heavy stuff over long miles. According to Mojamh AL Maani, the denotative meaning of the word al Jamal (the camel) is the type of animals which belongs to mammals with long neck and legs. The primary characteristic of al Jamal (the camel) is that it has one or two humps on the back. This type of animal usually lives in dry places. Therefore, it can survive for long periods without food or drinks. Besides the denotative meaning, the word al Jamal (the camel) has several figurative meanings of their usage based on the speakers' cultural perspectives. Some of these meanings are taking from the nature of the creation of 
these animals. Others have religious status by being mentioned in the Quran. The following are the most known figurative meaning for al Jamal (the camel).

\subsubsection{Patience}

For example, Al Jamal (the camel) is mentioned in the Quran in several places as an animal that symbolizes patience. The Quran praised its creation and invited people to contemplate its unique appearances in the following Qur'anic verse.

"أفلا ينظرون إلى الإبل كيف خلقت (surah Al-Ghashiyah: 17).

(Then do they not look at the camels how they are created?)

The above-mentioned Qur'anic verse is enough evidence that patience is one of the connotative meanings associated with this animal name. As can be noticed from this verse's meaning, such trait is attributed to camels based on the physical appearances that are unique to them.

\subsubsection{Hatred}

According to Arabic proverbs, it is well known that al Jamal (the camel) is used to refer to the hatred trait. A person who does not forget easily is usually referred to as al Jamal (the camel) by Arab culture. It is apparent in the following proverb.

$$
\text { أحقد من جمل }
$$

(More hateful than camel)

In addition to the Arabic proverb, the connotative meaning of al Jamal (the camel) as a symbol of hatred is also mentioned in Arabic poetry. Al-Kinani, one of the Arab poets, mentioned that in one of his poetry saying the following.

يبكي علينا ولا نبكي على أحد ...لنحن أغلظ أكباداً من الإبل

(we are cried for and we don't cry over anyone ... for we are tougher than the camels)

The poet metaphorically compares the ruggedness of his heart to the heat of Jamal (the camel). Such comparison implies that al Jamal (the camel) symbolizes hatred (cited in Arabian proverbs, 2014).

\subsubsection{Apparent/ Spread}

Another meaning but less expected is that al Jamal (the camel) refers to the activity that cannot be hidden, such as the activities done publicly in an overt manner. Specifically, it refers to the person who does actions that are impossible to be hidden. According to Mojamh AL Maani, it is said the following.

ما استتر من قاد الجمل

(who rids the camel can not hide).

The proverb above means that the camel rider is apparent and sighted; some actions cannot be hidden from the public. The connection of such a simile between camels and obvious things is based on this animal's large size.

\subsubsection{Working at Night}

One of the connotative meanings mentioned in the Arabic literature is that the term al Jamal (the camel) attributes the person who stays all night working. In other words, a busy person who works at night as compared to a person who rides a camel as if he rides the night. This meaning can be further illustrated by one of the meanings mentioned in Mojamh AL Maani. اتخذ الليل جملاً

(he took the night as a camel).

The proverb has the connotative meaning of a hard-working person who stays the whole night working.

\subsubsection{Being Neutral}

A further meaning of al Jamal (the camel) stated by Arabian proverbs as illustrated in the following Arabic proverb.

لا ناقة لي فيها ولا جمل

(there is no camel belongs to me in it)

This is one of the most well-known Arabic proverbs that shows the neutral stance of the speaker. The animal name here is used figuratively to refer to the act of objectivism and not being interfere in the matters. Therefore, speakers use such as expression to inform others that they did not interfere in the action at all as if he does not own any 
possessions such as camels.

However, the gender factor plays role in the interpretation of the animal names. For example, the feminine counterpart of al Jamal (the camel) has the connotation of beauty. In the ancient Arabic culture, they used to refer to the beautiful woman by calling her al nagha (the feminine camel). Al-ghaood (2012:114), in his book, referred to this meaning which indicated the symbolic meaning of beauty of al nagha (the feminine camel) although it is no longer being used recently.

\section{Al Asad (the Lion)}

Arabs appreciate the outstanding traits of Lions as they signify strength, courage, royalty, and ferocity. Therefore, this creature inspired many Arabs to name their babies after them. Al Asad (the lion) definition in Mojamh AL Maani is a wild animal that is very harmful. Such definition represents the denotative meaning of the word. However, the word has multiple figurative meanings. The following are the subsections where each denotative meaning represents separately.

\subsection{Courage}

Al Asad (the lion) generally has a positive connotation in Arab cultures. Ahmmad (2017: 45) stated that a person resembles a lion if he is courageous and brave. It can be proven by the fact that prophet Muhammad called his uncle Hamzah (Asad Allah) because it is associated with power and braveness. The association between this animal name and courage is based primarily on lions' brutal nature in general.

\subsection{Outstanding or Importance}

Al Asad (the lion) also refers to the outstanding and essential persons who can lead. One of the characteristics of the word in Mojamh AL Maani is the attribute of leadership, such as in the following proverb:

هم أسد الشرى

(they are the lions among their collogue)

The previous proverb depicts brave and influential people as lions, which is considered a positive connotation. The proverb also implies that they are the most important people in their surroundings.

\subsection{Inheritance}

The reference to the animal name Al Asad (the lion) is also found in Majma' al-amthal by Maydani (2013) in one of the most known Arabic proverbs in which the word is used to indicate sun and father resemblance. The resemblance is not restricted to physical appearances only; instead, it could also resemble the trait. Examine the following Arabic proverb.

هذا الشبل من ذاك الأسد

(this little lion from that lion)

Based on the mentioned proverb, Al Asad (the lion) refer to the father's similar personalities and behaviors, which are usually viewed positively. It is usually used when there are apparent similarities between the father and his son, whether in physical or personality traits.

\subsection{Ferocity}

Al Asad (the lion) also refers to the cruelty and savagery. According to Mojamh AL Maani, people in danger are between the lion's jaws, such as in the following Arabic proverb.

بين فكي أسد

(between the lion's jaws)

This proverb refers to the person who went through an unsafe situation, which is a considerable risk. The proverb gains its significance because lions are wild animals and are unsafe to deal with.

\subsection{Large Portion}

One of the famous connotative meanings of Al Asad (the lion) found in Mojamh AL Maani is a significant portion. Lion as an animal name implies the large portion or quantity of something. It says that a person has the lion share means that this person earns the most significant portion, as indicated in the Arabic proverb below.

حصة الأسد

(the lion's share) 
Due to the large size of such animals, the connection between this animal and the large portion existed. Therefore, the meaning here is inspired by the physical traits of lions as being large animals.

\section{Al Tays (The Goat)}

Since ancient times, goats are significant in the Arab community as a symbol of sacrifice. They also are valued for the products that they produced, such as skin, hair, and milk. The denotative meaning of Al tays (the goat) according to Mojamh AL Maani is a male mammal that turns a year old and gives milk and meat. However, it is one of the animals widely referred to in figurative speech in Arab cultures. The following are the most common connotative meanings that are associated with the word.

\subsection{Foolishness and Ignorance}

The Arab culture is referred to as the stupid person who does is hardily understand things by Al tays (the goat). Such meaning is implied from previous Arabic proverbs mentioned in Arabic literature, such as the following.

تيس في سفينة

(goat is in the ship)

Based on Arabic culture, there is a strong connotation between Al tays (the goat) and foolishness and naivety. This animal name refers to a person who suffers from a slow understanding or has some learning difficulties. It became part of Arab cultural terminologies that are used in every day.

\subsection{Misbehavior}

Another meaning of the word $\mathrm{Al}$ tays (the goat) is that it indicates a person's misbehavior. In other words, when a person does not know how to react appropriately, he is claimed to become a goat, as in the following proverb.

تيس فلان

(someone became a goat)

Like the meaning mentioned in the previous section, goat is an adjective used to attribute someone who resembles the goat in the misbehavior. There are more other cultural-bound meanings for this word, yet the already mentioned meanings are the most common in Arab culture.

\subsection{Haya (Snake)}

The literal definition of haya (snake) is a reptile that has a venomous bite. However, among the famous Arabic animals that have symbolic reference is haya (snake). However, this animal name is among the most used animal names in Arab culture with different connotations. Here are some of their meanings that have different connotations in Arabic culture.

\subsection{Intelligence}

A person who is called haya (snake) is inelegant and intelligent. As mentioned in Mojamh AL Maani, they compare the intelligent person's head to the snake's head in the following Arabic proverb.

رأسه رأس حية

(his head like a head of a snake)

Such a description is not a physical one; instead, it refers to the described person's mental state as intelligent and cunning. However, the word does not always have a positive reference. Below are some other meanings that have negative connotations that are existed in everyday life.

\subsection{Destruction}

Another less common meaning of the word is the meaning of the person's destruction attributed to the word haya (snake). Consider the following Arabic proverb mentioned in Majma' al-amthal, which can be evidence of the matter.

سقاه الله دم الحيات

(God watered him with the blood of the snake)

The mentioned proverb means that if the person metaphorically was watered with the snake's blood, it will be a sign of his destruction. In other words, this idiom refers to people who take risks doing risky actions without being afraid of their consequences. 


\subsection{Cunning}

Cunning is one of the attributes that is positively referred to smart people in Arabic culture. The Arabic literature is هich with sayings that imply this meaning, such as the following one. هيات الأرض

(they are the snakes of the earth)

The animal name haya (snake) is used in the previous idiom as a positive discerption of the knight person. It is known that a knight is a person who is cunning and therefore is an excellent candidate to be attributed by haya (snake).

\subsection{Protection}

Another meaning of the word haya (snake) documented in Mojamh AL Maani is the protection and security. This meaning can be evident by a proverb similar to the following one.

هو حية الو ادي

(he is the snake of the valley)

It means that this animal name can refer to the person who can guard the valley. As can be noticed, the word has a positive connotative meaning in this context.

\subsection{Nobility}

The word haya (snake) can also be referred to as the positive personal trait of being noble. Arabic culture is usually used to call a person who has a good quality by haya (snake), as can be seen in the example below.

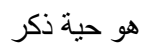

(he is a male snake)

However, gender plays a role in the symbolic meanings of the word haya (snake) because it had a negative connotation when it used to attribute a woman. One famous comparison by an Arabic intellectual, Al-rifai (2012), compared between snakes and the women that both are poisoning creatures where snakes poison by their teeth, women poison by their tongue.

\section{Al yrab (Crow)}

The definition provided in AL-Muajam AL-Wassit for al yrab (crow) is that this type of animal belongs to the birds, and it has many types. As mentioned before, the analyses care less about the word's denotative meanings; instead, what is more important is the connotative meanings of the given animal because of their variations. In general, al yrab (crow) in Arabic culture is viewed negatively. However, the following are the most common meanings related to this animal based on its occurrence in Arabic literature.

\subsection{Justice}

$\mathrm{Al}$ yrab (crow) is one of the animals praised in the holly Quran in its wisdom and justice in a famous story when Allah sends it to show how the dead body should be buried. Consider the following verse from Quran in surah (Al Maedah:31).

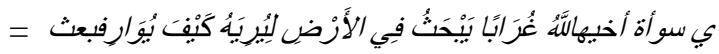

(and then God send a Crow digging in the ground to show him how he would have buried his brother's dead body)

The Quranic verse showed how God choose this animal specific to teach humanity this religious ritual. Even in science, al yrab (crow) is regarded among the most imaginative animals since they have a large brain size compared to other animals.

\section{$6.2 \mathrm{Bad}$ Omen}

One of the broader meanings of the al yrab (crow) is that it symbolizes bad omen. Arabs in the past might cancel their trip if they saw a crow before their traveling. Consider the saying mentioned in AL-Muajam AL-Wassit, which is the best evidence in this context.

غراب البين

(the misfortunate crow)

The previously mentioned saying indicates that al yrab (crow) is culturally viewed negatively as an unfortunate creature. Metaphorically speaking, if a person is pessimistic, people around him will refer to him as a crow. 


\subsection{Youth}

A less common meaning for al jrab (crow) is that it refers to the adolescence and youthfulness. Consider the following example which taken from AL-Muajam AL-Wassit which indicates that if a crew of a person has gone, it means that he is getting old.

طار غرابه

(his crow has gone)

The saying shows that al yrab (crow) symbolically refers to the young age, which is understood by saying that his growth has gone, which means that his youth has also gone. It is, however, one of the less common meanings of crow.

\subsection{Lateness and Carelessness}

A person is called by al yrab (crow) when he/she is lazy and carelessness. AL-Muajam AL-Wassit indicates this meaning in the following saying, which implies that crows are symbolically is known by their slowness and laziness.

أبطأ من غراب نوح

(slower than the crow of Noah)

The proverb shows that al jrab (crow) metaphorically refers to the slowness and lateness in performing things. Although the saying specifies a person who owns the crow, it still refers to the whole species in general.

\subsection{Fertility}

One of the meanings of the word (a less common one) is the meaning of fertility of something. Usually, the attribute of fertility here refers to objects, not people. The following proverb below shows that the fertile and productive land is referred to by this animal name.

أرض لايطير غر ابها

(the fertile land)

That is why anything that shows long-term life is being referred to this way. The symbolic connection between crow and fertility is that the physical appearance of crow never indicates age.

\subsection{Darkness}

People with dark skin are being called al yrab (crow), although it shows racism and is not preferable. One of the well-known Arabs who was attributed by this name is Antarah ibn Shaddad whom the crow of Arabs named mentioned in the following example.

أغربة العرب

(the crows of Arab)

The connotation between crow and dark skin is merely based on physical appearances. However, such adjectives should be completely avoided because it is highly racist.

\subsection{Sharp Vision}

According to Mojamh AL Maani, this kind of bird is well known for its sharp vision. Therefore, a person with a sharp visualization is usually called having crow's eyes, as indicated in the following Arabic proverb.

عين الغراب

(eye of the crow)

Because of this physical feature that crows possess, the connection between this attribute and people with sharp sights is established.

\subsection{The Sharpness of Something}

A less commonly used meaning of the word is referred to as the sharp edge of anything. Ancient Arab were called the sword's sharp edge as the crow sword as in the following proverb.

غر اب السيف

(the sharp sword)

However, it is not restricted to the sword only; instead, it refers to any sharp tools. This meaning, however, is 
metaphorical and hence cannot be taken literally.

\section{Qerd (Monkey)}

Unfortunately, monkeys carry bad reputations and are considered a symbol of ugliness in most middle eastern countries. Mojamh AL Maani provided the qared (monkey) connotative meaning, a mammal type that is the most similar to humans. This type of animal is good at mimicking other and very well known for their cleverness. The meaning is not restricted to the dictionary one; other meanings are culturally bounded summarized in the following subsections.

\subsection{Skillfulness}

Not all the meanings that are associated with the word qared (monkey) have negative connotations. One of which is the denotative meaning of skillfulness, which is usually associated with this kind of animal's considerable skills. Consider the following Arabic proverb.

فلان مثل القرد

(somebody is like a monkey)

It means that a person who has multiple skills is referred to as qerd (monkey). Such correlation takes place because of the ability of monkeys to mock others.

\subsection{Cunning}

As mentioned in the Arabic dictionary, cunning is one of the usages of the words' meaning. A deceived person is called qared (monkey), as shown in the following example.

قرد صاحبه

(he deceived his friend)

As noticed from the preceding example, it showed that qared (monkey) metaphorically referred to a person who can deceive others. Therefore, the maneuvering person is also referred to by this animal name because he is never direct.

\subsection{Gaining Money}

According to Mojamh AL Maani and Muajam AL-Wassit, the word refers to the person who collects things. The following example shows that this animal name calls the person who is collecting the money.

قرد المال

(collect the money)

however, this meaning is not restricted to collecting money only, yet it refers to the act of collecting anything.

\subsection{Ugliness}

As mentioned earlier in the study, the reference to a particular animal is part of its physical characteristics. Since qared (monkey) is among the ugliest animals, unbeautiful people are usually called by this animal's name. Consider the following proverb cited from Majma' al-amthal.

القرد بعين أمه غزال

(The monkey looks like a deer in the eye of his mother)

This proverb stated that the qared (monkey) is a symbol of ugliness in the Arab culture. In other words, the mother always sees her kids as beautiful as deer, although they might be not (looks like the monkey).

\subsection{Imitation}

The word qared (monkey) contains the meaning of imitation. The person who is good at imitating others is referred to by monkeys as in the following Arabic proverb.

زي القرد

(like a monkey)

it is because this attribute is part of the nature of this animal. Therefore, it became a characteristic for person who perfects mocking others.

7.6 Ruined

Among the rarely used meaning of qared (monkey), yet it has existed in Arabic literature, is the meaning of ruined. 
The ancient Arabs referred to the bad things by saying this animal name.

قرد الجلد

(the leather ruined)

It can also be used to refer to anything that is ruined or expired. People belonging to the same culture know that the term is used metaphorically, even if they never were exposed to it before. The context and shared background knowledge are fundamental here.

\subsection{Energetic}

One of the most used meaning for the word qared (monkey) is activity. The lively person that moves a lot is called qared (monkey), metaphorically. The following Arabic proverb is usually used in this context.

أعبث من قرد

(more missy than monkey)

In this case, the meaning carries a negative connotation since it refers to the annoying sense's activeness. Regarding the gender variable, there are no differences in qared (monkey) meanings when it addressed males or females. According to Arab cultures, the meanings remain the same regardless of the gender of the addressee. What matters is the context of speaking.

\section{Kalb (The Dog)}

Dissimilar to the shared beliefs, dogs are quietly respected in the Arab culture. In the ancient Arab world, dogs are used primarily for hunting purposes depends on their types. Dogs are literally defined as mammals that typically have a long nose, a strong sense of smell and know for their different types. The use of the name of this type of animal has different connotations. Some of which are positive, and the others have negative connotations. The following are the most common meaning used among people of Arab culture.

\subsection{Loyalty}

One of the positive references of the word kalb (the dog) is the symbolic meaning of loyalty. This meaning can symbolize by the following famous Arabic verse.

أنت كالكلب في حفاظلك للود وكالتيس في قراع الخطوب

(You are like a dog in your preservation of love and a goat in the field of engagement)

The previously mentioned verse is stated by the Arab poet Ali ibn Al Jahim praising the Abbasid caliph al-Mutawakkil. The verse might sound inappropriate and impolite, especially for the people who do not belong to the Arab culture and do not know about animal names' pragmatic function. However, it is widespread to use kalb (the $\operatorname{dog}$ ) as a symbol of faithfulness and reliability.

\subsection{Taking Things Back}

Unlike the previous meaning of the kalb (the dog), which indicates positive meaning, the word has another negative connotation for the people who take things back. This trait has been mentioned by the prophet Mohammad who criticized it and described it as a negative trait. Prophet Mohammad described the people who asked for what they gave back as the dog who eats his vomit. Although this meaning is less common; yet, it indicates one of the unpreferable traits in Arab culture.

\section{Hisan (Horse)}

Throughout Arab history, horses are considered to be a symbol of grace, persistence, and endurance. Their body structure reflects their extreme physical power. Such traits align with the definitions provided in both dictionaries Mojamh AL Maani and AL-Muajam AL-Wassit, which defined the word as a type of mammals used for riding, racing, and carrying and pull loads. However, a horse's name has many other connotative meanings as occur in Arabic literature described below.

\subsection{Uniqueness}

Since ancient times hsan (horse) is a symbol of uniqueness and distinguished person. It is widespread to call a person who is genuine by a horse.

مثل الخيل الأصيل

(genuine like a horse) 
Horses are ancient animals that join several competitions such as racing and riding. Arabs since ancient times use horses for both wars or pleasure events. Therefore, hsan (horse) has the reference of authentic and the good values of ancient people.

\subsection{Opposing}

The person who goes against the current is called hsan (horse). In addition to if the person is not good at putting things in their correct places is also named hsan (horse). Such meaning can exemplify in the following proverb taken from Majma' al-amthal.

وضع العربة أمام الحصان

(he put the wagon in front of the horse)

As shown from this example, this proverb is referred to the person who is good at reversing others. A Nonconformist person is said to but things against what they should be.

\subsection{Strength}

The reference of the word to strength is attributed to females. The gender factor plays a role in identifying the metaphorical meaning of the word. The meaning of the word is different if it is referred to males or females. As shown in the discussion above, the word carries positive connotations when it refers to males, whereas it carries negative meanings when referred to females. It refers to a wild woman who is hardily tamed, which is in a way or another goes back to this animal's physical characteristics, which is known for its strength and powerfulness.

\subsection{Courage}

One of the common meanings of the word hsan (horse) is associated with courage and bravery. The person who speaks up in a challenging situation is called hsan (horse). This name attributes the person, usually the head of his people. The horse's symbolic meaning is being a leader came from one of the physical functions of horses as pulling horse wagons. It is strong evidence that most of the metaphorical meanings of words derived from their literal meanings at first hand, then these meanings became common.

\subsection{Measurement unit}

The word is also used scientifically to refer to a measurement unit that is used to indicate strength. This unit's strength is known to the specialist people, although it is familiar to laypeople. The mechanical horse is a unit of measurement used in physics, and it is a unit of measurement for power. The official unit for measuring power is the watt, and since ancient times the mechanical horse has been used as a unit of power, and the mechanical horse equals seven hundred and forty-six watts, which is 0.746 kilowatts.

\section{Xruof (Sheep)}

Sheep is another vital animal for Arabs. it is explained by the fact that sacrificing such an animal is one of the religious rituals they believe. Sheep is defined in the dictionary as a mammal with a wooly coat with curvy horns. However, the interest of the paper is focused mainly on the cultural meanings of the word. The following are the most used symbolic meaning that the word might indicate.

\subsection{Fat Person}

A person who is fat is usually referred to as xruof (sheep). More specifically, it is used to refer to a fat child as the Eid's sheep. Examine the following Arabic idiom that is frequently used in this context.

خروف العيد

(the sheep of the Eid)

Nevertheless, calling a child by a sheep does not carry a negative connotation in Arab culture. Instead, it carries the meaning of cute choppy child, which is very acceptable culturally. It is more common, however, to use this animal name to call kids than adults.

\subsection{Followers}

The very well-known meaning of xruof (sheep) is the meaning of followers. Sheep are known for their tendencies to follow others in the flocks. According to Mojamh AL Maani, in the context of a person who is not a decision-maker is called xruof (sheep), as can be seen from the following Arabic proverb.

انقادو كالخراف

(they been led like sheep) 
As the example showed, the non-conformist person is metaphorically referred to by xruof (sheep) symbolically. Some of the cultural connotations of the animal names are similar to other cultures. The above-mentioned Arabic idiom is very similar to the one that existed in the western culture, "head of the herd." Both idioms' meanings are almost the same, which means that a person is a sheep if he follows others and does not have his personality.

\subsection{Luxurious People}

A less common metaphorical meaning of xruof (sheep), according to Muajam AL-Wassit, is the reference of the word to the luxurious people. Consider the following proverb that compares lucky people to sheep.

كالخروف، أينما اتكأ اتكأ على صوف

(like the sheep where they lean, they lean on wool)

The proverb showed how this animal name indicates the comfortable lifestyle of the person who is being called by. It implies that the person called sheep the luck is always by his side, similar to the sheep who has wool and can lay on it wherever they move.

\subsection{Cowered}

A not preferable meaning of the word xruof (sheep) is referred to the husband who is under his wife's dominance. Like in:

زوجها مثل الخروف

(her husband is like a sheep)

Such cultural bound reference between the dependent husband and sheep is due to the xruof (sheep) ' natural characteristics (sheep), which are followers. Therefore, it is a common thing to refer to a weak and controlled person by such reference.

\section{Arnab (Rabbit)}

Rabbits are associated with burrowing, gnawing, and taking up space in Arab culture. Nevertheless, the dictionary meaning of arnab (rabbit) is a plant-eating mammal with long ears, long hind legs, and a short tail producing a lot. However, the meaning of the word is not restricted to the dictionary's meaning; somewhat, many other meanings are socially restricted. The following are the most common meaning related to arnab (rabbit).

\subsection{Cowered}

The animal arnab (rabbit) is used symbolically to refer to a weak and cowered person who afraid of confronting others. The following Arabic idiom is very common in describing the person who is characterized by this trait.

إنما هو أرنب

(he is a rabbit)

According to Arabic culture, this is not a desirable trait which is usually avoidable. The age in this case does not matter since both kids and adults can be called by this animal name if they are believed to be cowered.

\subsection{Fertility}

Another meaning that is associated with arnab (rabbit) is the connotation of fertility. As the term suggests, this meaning is associated with females more specifically. In Arabic culture, a woman who gives birth to many children is referred to by a rabbit as the subsequent idiom.

الإنجاب الأرنبي

(the reproduction of rabbit)

Such reference does not have a bad connotation at all. On the contrary, it is considered as praising a woman as being fertile.

\subsection{Fastness}

Throughout Arabic folk stories, rabbit is the most frequently used animal name that indicates the fastness and quickness. Therefore, a fast person is usually called a rabbit. Consider the following Arabic proverb, which indicates this meaning.

أسر ع من أرنب

(faster than rabbit) 
The association between fastness and rabbit is due to the physical feature that characterized the rabbit in this regard. That is why this is one of the idioms that have a predictable meaning.

\section{Conclusion}

Words gain their importance not only from their literal meaning; instead, they gain their importance from the meaning associated with them. Therefore, the connotation meaning is equally important as the denotative meaning (Husam Al dain, 1980). Accordingly, the present study focused on the culturally bounded animal names. As shown in the analyses of the animal names, some are used positively while others are used negatively depending on the culture and context and the gender factor, which plays a role in altering the meaning of the same word. Just as stated in Hsieh's (2006) study, animal expressions are viewed based on their semantics within certain culture. It showed how the different connotative meanings of animal names and correlations between them and human traits are culturally bounded.

However, evaluating the animal name's exact meaning is risky because it depends heavily on the speaker's culture. In agreement with previous studies by Nesi (1995) and Halupka-Resetar and Radic (2003), animal names have metaphorical uses that are based on the connotative meaning related to the speakers' cultures. Animal characteristics, for example, such as size, eating habits, and intelligence are the main motivations of the metaphorical transfer of their names to humans. The cultural-bound meanings of the animal names are derived from their existence in Arabic literature. Therefore, these animal names reflect the speakers' cultures, views, beliefs, and social thoughts. Such a conclusion goes in line with Al-makaui (2007)'s study who stated that names may gain their importance from religious context since they reflected people's religious background. Arabs embraced their power and strength by calling themselves strong names because it was believed that the person has part of its name.

\section{References}

Ahmmad, A. (2017). The semantic creativity in the opposites. UAE: Al Manhal.

Al-ghaood, F. (2012). The language of poetic discourse in Jamil Buthaina .UAE: Al Manhal.

Al-Harahsheh, A., \& Al-Rousan, M (2020). Animal names used to address people in Jordanian spoken Arabic. Dirasat, Human and Social Sciences,47(1), 328-336. https://doi.org/10.35516/0103-047-001-045

Al-makaui, A. (2007). The environment and the Names: a study of the meanings and the] semantics. Cairo: Kotobarabia.

AL-Muajam.AL-Wassit. (2014). Retrieved from http://arabianproverbs2014.blogspot.com/2016/07/blog-post_17.html

Al-rifai, M. (2012). Alafie is talking about the poison of women and snake. Retrieved from http://www.lahaonline.com/articles/view/40819.htm

Al-Salem, M. Ali, E., \& Alrashdan, I. (2010). The Connotations of Bird Names in Arabic and English. Manuscript submitted for publication. Retrieved from https://www.researchgate.net/publication/342865952_The_Connotations_of_Bird_Names_in_Arabic_and_Engl ish

Ben Salamh, S., \& Maalej, Z. (2018). A cultural linguistics perspective on animal proverbs, with special reference to two dialects of Arabic. AWEJ for Translation and Literary Studies, 2(4), 21-40. https://doi.org/10.24093/awejtls/vol2no4.2

Garro, L. C. (2000). Remembering what one knows and the construction of the past: A comparison of cultural consensus theory and cultural schema theory. Ethos, 28(3), 275-319. https://doi.org/10.1525/eth.2000.28.3.275

Halupka-Resetar, S., \& Radic, B. (2003). Animal names used in addressing people in Serbian. Journal of Pragmatics, 35(12), 1891-1902. https://doi.org/10.1016/S0378-2166(03)00052-3

Hsieh, S. (2006). A corpus-based study on animal expressions in Mandarin Chinese and German. Journal of Pragmatics, 38(12), 2206-2222. https://doi.org/10.1016/j.pragma.2006.08.007

Husam Al dain, K. (1980). Semantic analysis: Its procedures and methods. Kotobarabia.

Maydani, A. (2013). Majma' al-amthal. Cairo: al-Matba'a al-Khairiyya.

Mojamh AL Maani. Retrived from https://www.almaany.com/en/dict/ar-en/al-maani/

Nesi, H. (1995). A modern bestiary: A contrastive study of the figurative meanings of animal terms. English Language Teaching Journal, 49(3), 272-278. https://doi.org/10.1093/elt/49.3.272 
Nishida, H. (1999). Cultural schema theory: In W.B. Gudykunst (Ed.), Theorizing About Intercultural Communication, (pp. 401-418). Thousand Oaks, CA: Sage Publications, Inc.

Omar, Y. Z. (2012). The challenges of denotative and connotative meaning for second-language learners. ETC: A Review of General Semantics, 69(3): 324-351.

Pinker, S. (1988). A computational theory of the mental imagery medium. In: M. Denis, J. Engelkamp, J. E. Richardson (Eds.), Cognitive and neuropsychological approaches to mental imagery. NATO ASI Series (D: Behavioural and Social Sciences), vol 42. Dordrecht: Springer.

Ringmar, E. (2016). How the world stage makes its subjects: An embodied critique of constructivist IR theory. Journal of International Relations and Development, 19, 101-115. https://doi.org/10.1057/jird.2015.33

Sameer, I. (2016). A cognitive study of certain animals in English and Arabic proverbs: A comparative study. International Journal of Language and Linguistics, 3(5): 133-143.

Shamsutdinova, E., Martynova, E., Eremeeva, G., \& Baranova, A. (2017). Proverbs and sayings related to animals in Arabic, English and Tatar Press. The Turkish Online Journal of Design, Art and Communication TOJDAC, 799-804.

\section{Copyrights}

Copyright for this article is retained by the author(s), with first publication rights granted to the journal.

This is an open-access article distributed under the terms and conditions of the Creative Commons Attribution license (http://creativecommons.org/licenses/by/4.0/). 